NOTICE: this is the author's version of a work that was accepted for publication in Energy Policy. Changes resulting from the publishing process, such as peer review, editing, corrections, structural formatting, and other quality control mechanisms may not be reflected in this document. Changes may have been made to this work since it was submitted for publication. A definitive version was subsequently published in Energy Policy, Vol. 65 (2014).

DOI: 10.1016/j.enpol.2013.10.014 


\title{
The Asia Pacific Natural Gas Market: Large Enough for All?
}

\author{
Roberto F. Aguilera ${ }^{1}$, Julian Inchauspe ${ }^{2}$ and Ronald D. Ripple ${ }^{3}$
}

(1) Curtin Research Fellow, The John Curtin Institute for Public Policy, Curtin Business School, Curtin University, GPO Box U1987, Perth, 6845 WA, Australia. Tel.: +61 89266 9137, fax: +61 89266 1100, e-mail: R.Aguilera@curtin.edu.au, postal address

(2) Lecturer, Department of Economics, Curtin Business School, Curtin University, GPO Box U1987, Perth, 6845 WA, Australia. Tel.: +61 89266 9976, e-mail: Julian.Inchauspe@curtin.edu.au

(3) Professor of Energy Economics, Department of Minerals and Energy Economics, Curtin Business School, Curtin University, GPO Box U1987, Perth, 6845 WA, Australia. Tel.: +61 89266 3935, e-mail: R.Ripple@curtin.edu.au

$(*)$ : Corresponding author

\begin{abstract}
Among natural gas producing nations, there has been some concern about how the Asia Pacific will meet future demand for energy. We argue that natural gas, both regional and global, will play a vital role. Estimates of potential gas consumption in the region are analyzed and used to develop consensus projections to 2030. These consumption profiles are compared with gas supply estimates including indigenous, pipeline and LNG for the Asia Pacific market. From this analytical framework, we find that demand will be sufficiently large to accommodate supplies from diverse sources including North America, the Middle East, Central Asia, Russia, and the Asia Pacific itself. An important policy implication is that gas producing and consuming nations should benefit from promoting gas trade and not be concerned about a situation of potential lack of demand coupled with oversupply.
\end{abstract}

Keywords: Asia Pacific natural gas; demand; supply. 


\section{INTRODUCTION}

There are many concerns and uncertainties about natural gas markets. This paper tackles specific concerns about the future role of natural gas in the Asia Pacific region in regards to demand, supply, pricing, policy and energy security. Before emerging into the core technical analysis, a brief introduction to the topic is given.

The last two decades have been characterized by an upwards trend in world primary energy consumption. Much of this growth has originated in the Asia Pacific region which has exhibited a growth rate in primary energy consumption that is higher than the world average. For 2011, this growth rate has been estimated at $5.4 \%$ for the Asia Pacific region and at $3.1 \%$ for the world as a whole (BP 2012a). This dynamic pattern has been associated with high income growth and population growth and is expected to prolong in the future. A study by Aguilera and Ripple (2013) has analyzed in detail the trends for primary energy consumption and natural gas consumption in the Asia Pacific region; these historical and projected trends are summarized in figure 1. It shows the regional population, which has been increasing steadily since 1965 , as well as historical and projected future energy consumption. The upper curve is actual Asia Pacific primary energy consumption per year. Since 1965, the average increase in total energy consumption has been in the order of $10.9 \%$ per year. Presently, there is rapid demand growth and it is estimated that energy consumption per capita will rise to approximately 80 million British thermal units (BTU) per year by 2030 (middle curve, Figure 1). The lower curve shows the actual Asia Pacific population from 1965 to the present and a forecast to 2030. This extrapolation gives a figure of about five billion people by 2030 . 


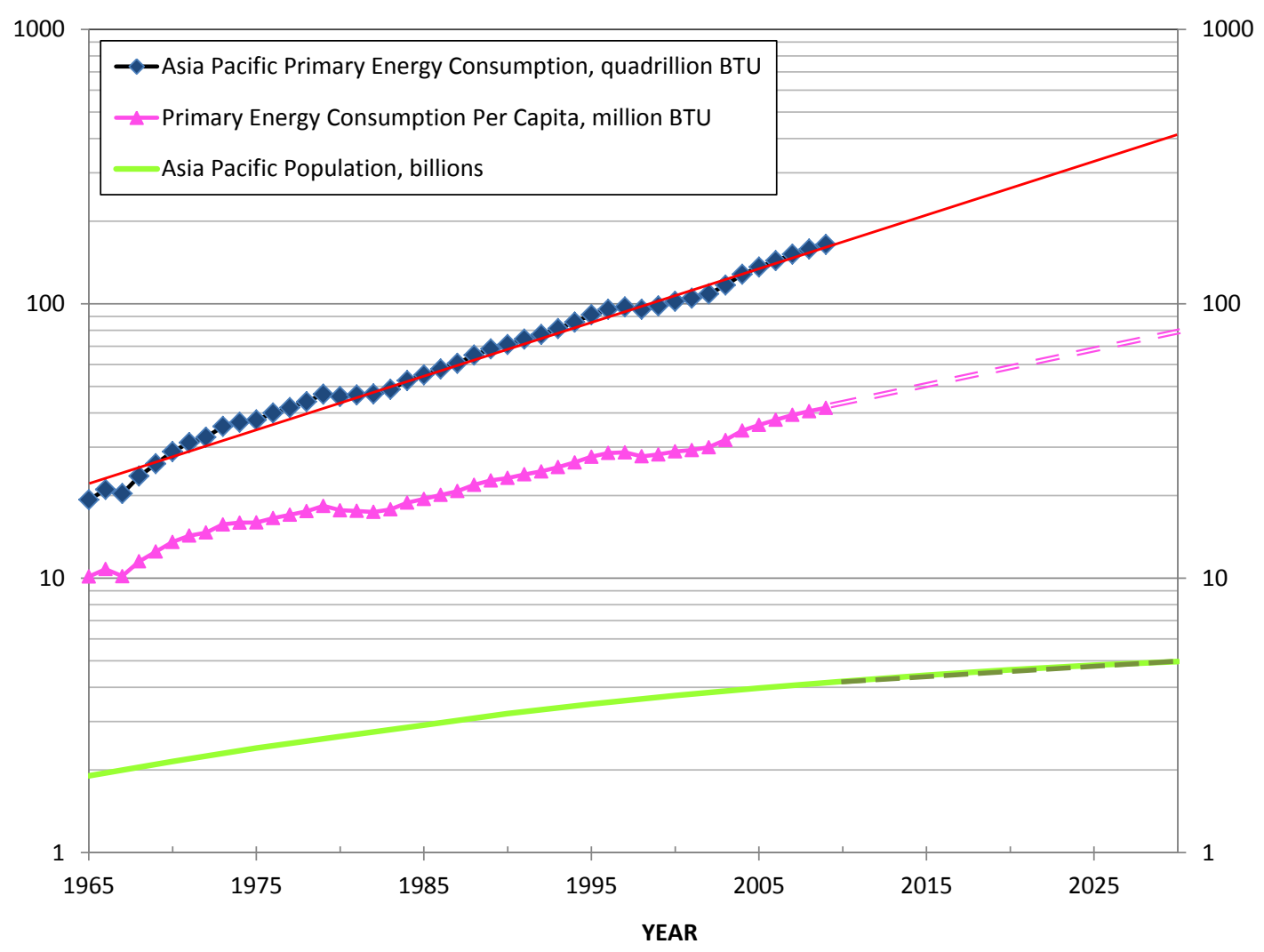

Figure 1- Population and energy consumption (Aguilera and Ripple, 2013).

So far, economic growth in the Asia Pacific region has mostly been fueled by coal and to a lesser extent oil. However, the importance of natural gas is expected to increase dramatically. Natural gas offers some advantages when it is compared to oil and coal. First, infrastructure development that allows for setting national and international contracts for the provision of natural gas brings energy security into the Asia Pacific region. Second, the latest technical developments in the production of shale gas that combine horizontal drilling with hydraulic fracturing have shown that it is possible to develop shale gas at an economically viable cost. In some US fields, producing shale gas is already cheaper than the average cost of developing conventional gas resources in that country, and the US is now expected to become a net exporter of natural gas in the future. Third, natural gas energy produces less carbon dioxide emissions than oil and coal, making it easier for policy makers to meet environmental targets. 
However, in order to reap most of the technical, political and environmental advantages that natural gas has to offer, several barriers will have to be overcome. These obstacles include limited gas delivery infrastructure, lack of competition and transparency, high transportation costs, lack of storage facilities, underdeveloped or inflexible markets, and limited legal and regulatory frameworks.

In spite of the challenges, some gas producing nations are concerned that perhaps demand in the region will not be sufficiently large to accommodate all possible supply sources. For example, there is some worry in Australia that its LNG supplies might not be needed in the coming decades by the traditional customers such as Japan, South Korea and China. The latter is particularly worrisome as China would be the most important customer by 2020 (BREE, 2012). However, China also has a significant conventional and unconventional natural gas endowment of its own. According to US EIA (2013a), the Chinese shale gas endowment is the largest in the world at 1,115 trillion cubic feet (TCF). To put that quantity into perspective, consumption of natural gas in China during 2011 was approximately 3.6 TCF (BP, 2012a). If China were to successfully develop its unconventional gas endowment, as well as sizeable conventional gas reservoirs, such that indigenous gas makes a significant contribution to its energy portfolio, then in theory demand for imports would fall. This is the concern that potential gas producing regions are faced with.

The uncertainty associated with the belief that natural gas demand in the Asia Pacific region might not be large enough to accommodate supply is an additional obstacle for the development of gas resources. This paper addresses the problem by analyzing the Asia Pacific gas markets in detail. We argue that the problem has two dimensions. First, it is necessary to carry out a thorough evaluation of the projected gas demand in this region and the potential supply from the entire world into it. Second, we need to 
analyze the pricing mechanisms in the Asia Pacific to see if oversupply or supply shortages will be likely to occur, and what policies might be needed. By analyzing this two-dimensional problem, this paper aims at contributing towards reducing uncertainty about the issue while highlighting the key energy policy issues that will need to be addressed.

The balance of the paper is organized as follows. Section 2 discusses the methodology. In Section 3 "consensus trends" for natural gas demand and supply to 2030 are elaborated and discussed. Section 4 discusses natural gas pricing mechanisms and implications of the trends from Section 2 for pricing, energy security and policy. Conclusions and discussions are presented in Section 5.

\section{METHODOLOGY}

The main part of this paper is concerned with demand and supply forecasts to 2030. Technically speaking, the simplest forecast one can think of is a linear trend projection, as shown in Figure 1. However, this simplistic approach may not be good enough. There are many physical, regulatory and economic factors that need to be controlled for in a realistic forecasting model. As realistic assumptions are incorporated, a large-scale natural gas market model becomes increasingly complex to the point that a large team of expert researchers is needed to develop it. The three researchers of this paper chose an alternative simplified approach. We consider some of the most important models that have been elaborated by leading teams of experts and average out their projections to obtain "consensus" projections of demand and supply for the Asia Pacific region. Other researchers have combined forecasts statistically, though these formal techniques are most applicable in other areas (see Clemen, 1989, for a review). The projections obtained through our method contain information on how a large 
number of researchers have factored in the most important characteristics of the Asia Pacific natural gas market. We find that the projections taken into account are very consistent. At the same time, considering different sources allows us to obtain lower- and upper-bounds estimates that are useful for analysis.

In a second step, these "conceptual projections" are used to address specific questions. Based on projected natural gas consumption in the Asia Pacific until 2030 and its respective potential supplies, we will analyze if consumption in the region will be large enough for both indigenous gas and imports from other gas producing regions. Will demand in China be so big that in addition to its own resources it will require imports from other Asian countries and the rest of the world? Our scope is regional, so it is important to also consider other large Asia Pacific customers like Japan, South Korea, India, and Southeast Asian nations. The total consumption figures are then compared with projections until 2030 of indigenous and pipeline gas, as well as LNG, to get an idea of the demand and supply balance. To finalize our analysis, we consider the potential implications of our projections for pricing, energy security and policy.

\section{DEMAND AND SUPPLY PROJECTIONS OF NATURAL GAS FOR THE ASIA PACIFIC REGION}

Consumption of natural gas in the Asia Pacific will grow significantly faster than in any other part of the world. For instance, gas demand in China is forecasted to double within the next five years (BREE, 2012). By 2030, the Asia Pacific will be the world's largest consumer of natural gas despite the likelihood that coal and oil will each still occupy a larger market share. Table 1 presents estimates of consumption as reported by IEA (2012), BP (2013) and ExxonMobil (2012). The quantities are relatively close, ranging from 41.4 to $41.7 \mathrm{TCF}$ with an average of $41.5 \mathrm{TCF}$. 
Table 1: 2030 Natural gas demand projections for the Asia Pacific

\begin{tabular}{|l|c|}
\hline Source & 2030 Demand (TCF) \\
\hline International Energy Agency (2012); new policies scenario & 41.5 \\
British Petroleum (2013) & 41.4 \\
Exxon Mobil (2012) & 41.7 \\
\hline Average & 41.5 \\
\hline
\end{tabular}

The next step is to present estimates of production in the Asia Pacific by 2030. Projections by BP (2013), IEA (2012) and US EIA (2013b) are reported in Table 2 and range from 24.8 to 31.7 TCF with an average of about 28.6 TCF. Importantly, the total accounts for gas production from both conventional and unconventional formations. Australia, expected to be the world's largest LNG exporter by 2020 (Platts, 2013), is part of the Asia Pacific and thus included in the projections of Table 2. It is assumed that the gas produced in the Asia Pacific will be consumed within the region (i.e. the production quantities are unlikely to be exported to other regions).

Given that consumption is projected to average 41.5 TCF, this implies that almost $70 \%$ of the Asia Pacific market will be supplied by the region itself. The remaining consumption volume of about 12.9 TCF will have to come from non-Asia Pacific sources. 
Table 2: 2030 Natural gas regional supply projections for the Asia Pacific

\begin{tabular}{|l|c|}
\hline Source & 2030 Regional Supply \\
& (TCF) \\
\hline US Energy Information Administration (2013b); reference case & 24.8 \\
International Energy Agency (2012); new policies scenario & 29.2 \\
British Petroleum (2013) & 31.7 \\
\hline Average & 28.6 \\
\hline
\end{tabular}

Table 3 shows estimates made by several organizations about the possible natural gas supply to the Asia Pacific. The sources are expected to come primarily from Central Asia (mostly Turkmenistan), Russia, North America (US and Canada), and the Middle East (primarily Qatar). It is also probable that East African nations Mozambique and Tanzania will deliver LNG to the Asia Pacific by 2030, though the relatively small quantities do not alter our results. Given the uncertainty of forthcoming supply, separate columns for low and high estimates are shown. Some of the determinants of supply quantities include gas delivery infrastructure, storage capacities, market development and flexibility, and legal/regulatory frameworks. As shown in Table 3, the total exports to the Asia Pacific range from 8.4 to 13.3 TCF. Adding the low and high estimates to the average Asia Pacific production from Table 2 gives total supply quantities of 37.0 TCF and 41.9 TCF, respectively. 
Table 3: 2030 Asia Pacific natural gas import projections

\begin{tabular}{|l|c|c|}
\hline \multirow{2}{*}{ Area } & \multicolumn{2}{|c|}{ 2030 Supply to Asia Pacific (TCF) } \\
\cline { 2 - 4 } & Low & High \\
\hline Central Asia & 1.8 & Platts (2011) \\
\hline Russia & IEA (2011), New Policies Scenario & 2.3 \\
\hline North America & MIT (2011), Reference Scenario & IEA (2011), New Policies Scenario \\
\hline Middle East & 1.8 & TOTAL (2012) \\
\hline Total & BP (2012b) & D.9 \\
\hline
\end{tabular}

Given the data presented to this point, it is possible to make an evaluation about whether the Asia Pacific natural gas market will be big enough to accommodate all supply sources. This is carried out through a supply and demand balance represented by the following equation:

$A P D-A P P-A P M_{(\text {low or high) }}=R E S$

where $A P D$ is the total gas demand in the Asia Pacific, $A P P$ is the indigenous gas production in the Asia 
Pacific, $A P M_{\text {(low or high) }}$ is the gas quantity imported by the Asia Pacific (either low or high estimate from Table 3), and RES is the residual gas quantity.

Assuming the low case import projection from Table 3, the equation gives the following result in TCF: $41.5-28.6-8.4=4.5$. The excess demand of 4.5 TCF implies that the market is large enough for all producers, though a supply shortfall would be anticipated. The high case import projection result is as follows: $41.5-28.6-13.3=-0.4$. In this case, there is slight oversupply of 0.4 TCF. However, the import figure is more likely to be somewhere between the upper and lower case. Using the average of the low and high projections, equal to 10.9 TCF, results is excess demand of 2.0 TCF $(41.5-28.6-10.9=2.0)$.

To put these figures into perspective, recent trade volumes are given in Table 4. Asia accounts for nearly $63 \%$ of total LNG shipping and only $6.2 \%$ of pipeline trade. In total, Asia Pacific imports about 7.3 tcf of LNG and 1.5 tcf of natural gas through pipelines per year. But once intraregional trade is deducted from total imports, Asia Pacific net imports from the rest of the world become 5.3 tcf of LNG and 0.5 tcf of natural gas transported through pipelines. These figures provide an account of the limitations of current infrastructure capacity, which is fully utilized. By comparing the average predictions from Table 3 and the figures of Table 4, we conclude that LNG and pipeline import infrastructure capacity will have to increase between $44.8 \%$ and $129.3 \%$ by 2030 . Limitations in infrastructure will have implications for pricing as Asia moves to a more liberalized market. 
Table 4: Natural gas imports into Asian countries in 2011, in billion cubic feet (Source: British Petroleum, 2012a)

\begin{tabular}{|c|c|c|c|c|c|c|c|c|c|c|c|c|c|c|c|c|}
\hline \multirow{2}{*}{ 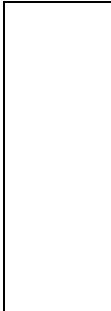 } & \multirow{2}{*}{$\begin{array}{l} \\
\text { Destination } \\
\text { Country }\end{array}$} & \multicolumn{15}{|c|}{ Imports from } \\
\hline & & 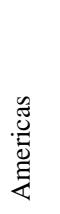 & 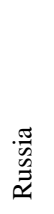 & 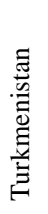 & ฏี & 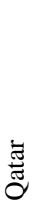 & 壳 & 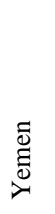 & 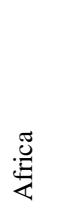 & 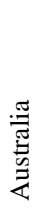 & 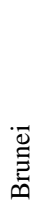 & 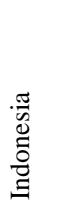 & 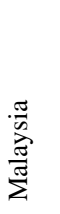 & 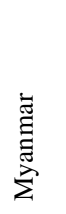 & $\begin{array}{l}\bar{\Xi} \\
\overline{0}\end{array}$ & 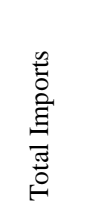 \\
\hline \multirow{6}{*}{ 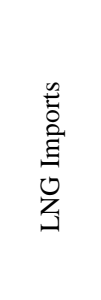 } & China & 28.3 & 10.6 & - & - & 113 & - & 38.8 & 49.4 & 177 & - & 95.3 & 74.2 & - & - & 586.2 \\
\hline & India & 35.3 & - & - & 3.5 & 459 & 7.1 & 7.1 & 77.7 & 7.1 & - & - & 7.1 & - & 3.5 & 603.9 \\
\hline & Japan & 49.4 & 346 & - & 191 & 558 & 272 & 10.6 & 201 & 671 & 297 & 445 & 717 & - & 24.7 & 3778.7 \\
\hline & Korea & 120 & 138 & - & 177 & 392 & - & 131 & 113 & 38.8 & 35.3 & 381 & 198 & - & 17.7 & 1741.0 \\
\hline & Taiwan & 7.1 & 10.6 & - & 7.1 & 187 & 3.5 & 7.1 & 84.8 & 14.1 & - & 91.8 & 159 & - & 10.6 & 575.6 \\
\hline & Thailand & 10.6 & 7.1 & - & - & 10.6 & - & - & 7.1 & - & - & 3.5 & - & - & - & 35.3 \\
\hline \multicolumn{2}{|c|}{ Asia LNG Imports } & 247 & 509 & - & 187 & 381 & 1716 & 279 & 191 & 526 & 904 & 332 & 1017 & 1158 & 187 & 7320.7 \\
\hline \multicolumn{2}{|c|}{ World LNG Imports } & 918 & 509 & - & 509 & 385 & 3637 & 283 & 2013 & 915 & 332 & 1031 & 1176 & - & 187 & 11682.1 \\
\hline \multirow{5}{*}{ 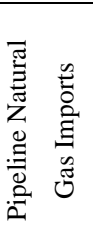 } & China & - & - & 505 & - & - & - & - & - & - & - & - & - & - & & 505.0 \\
\hline & Hong Kong & - & - & - & - & - & - & - & - & - & - & - & - & - & 109 & 109.5 \\
\hline & Malaysia & - & - & - & - & - & - & - & - & - & - & 70.6 & - & - & & 70.6 \\
\hline & Singapore & - & - & - & - & - & - & - & - & - & - & 237 & - & - & 81.2 & 321.4 \\
\hline & Thailand & - & - & - & - & - & - & - & - & - & - & - & - & 304 & & 303.7 \\
\hline \multicolumn{2}{|c|}{ Asia Pipeline Imports } & - & - & 505 & - & $\cdot$ & - & - & - & $\cdot$ & - & 307 & $\cdot$ & 304 & 191 & 1525.6 \\
\hline \multicolumn{2}{|c|}{$\begin{array}{l}\text { World Pipeline } \\
\text { Imports }\end{array}$} & 4556 & 7310 & 505 & - & 678 & - & - & 1504 & - & - & 307 & 304 & 304 & 8016 & 24529.6 \\
\hline
\end{tabular}

A study by the International Energy Agency (2013) has analyzed planned and under-construction infrastructure in Asia. Plans for pipeline infrastructure development are vast and far-reaching but subject to a large degree of uncertainty (most of these projects are long-term and managed by governments). Generally speaking, LNG infrastructure is more adaptable in the Asia Pacific.

Substantial pipeline development covering over $12,500 \mathrm{Km}$ is currently under way, including: the $2,800-$ Km Altai gas pipeline between Russia and China with transportation capacity of about 1 tcf of natural gas per year; the 1,735-Km Turkmenistan-Afghanistan-Pakistan-India Pipeline (TAPI) with capacity of 
950 bcf per year annually; the 1,035-Km Iran-Pakistan-India pipeline carrying 1.9 tcf per year; and the Trans-Caspian gas submarine pipeline connecting Turkmenistan (China's major partner) with Russia and Turkey (although this project is facing political opposition at the moment); and other developments such as the Sabah-Sarawak Gas pipeline in Malaysia, the Trans-Thailand project, the Malaysia-Korea pipeline and the Yacheng-Hong Kong pipeline, among others. There are longer-term plans for interconnecting all the pipelines above. This ambitious project is known as the Trans-ASEAN gas pipeline (TAPG) project, and is not expected to materialize before the mid-2020s. Slow progress and delays in meeting past objectives raise serious questions about the realistic magnitude, scope and phase deadlines of the project.

In the shorter term, increases in Asia Pacific natural gas imports will most likely occur through LNG shipping. The LNG regasification and storage facilities are individually too small and numerous to be listed in this document, but it is worth emphasizing that China, Japan and South Korea are making significant progress in terms of increasing their import capacity. In Australia, new liquefaction infrastructure is under construction in Barrow island and Karratha on the West coast, and in Gladstone on the East coast. Australia is currently exporting LNG from its North West Shelf, but considerable development of coalbed methane and associated LNG exporting facilities is under way in the East.

\section{PRICING AND POLICY IMPLICATIONS}

Natural gas pricing around the globe has historically been rather divergent; a comprehensive discussion of the different economic market structures that have been applied around the world may be found in Dahl (2004). It has been the view of many analysts that North America constitutes a relatively highly 
competitive market structure, while Europe is better represented as more oligopolistic (with considerable State participation at all stages of the supply chain), and the Asia Pacific is only slowly evolving from a structure of several bilateral monopolies, with Japan the original and dominant player in the region. North American natural gas trade is conducted primarily through a highly integrated transportation pipeline network reaching into nearly all corners of the United States (with the exception of New England), and containing substantial links into Canada and to a lesser extent Mexico. Through displacement and backhaul mechanisms, natural gas from nearly anywhere on the continent can find a market in any part of the continent. Neither Europe nor the Asia Pacific yet has this degree of market integration or the degree of gas-on-gas competition that it supports.

In North America, most natural gas is sold under arrangements that include a pricing mechanism tied to the price of natural gas quoted at Henry $\mathrm{Hub}(\mathrm{HH})$, Louisiana. European natural gas pricing has been largely based on links to oil products like fuel oil, rather than the gas-on-gas pricing that evolved in North America in the 1980s. There is some movement in Europe away from oil-based pricing, but the progress toward hub-based, gas-on-gas pricing appears to be slow. Some exceptions are observed, especially for natural gas trade in the United Kingdom. In the UK, natural gas is priced against the so called National Balancing Point (NBP), which unlike $\mathrm{HH}$, is a virtual pricing point within the UK pipeline grid, as opposed to the physical location in Louisiana.

Natural gas trade in the Asia Pacific began with LNG imports into Japan from Kenai, Alaska, United States, in 1969. Supply sources for LNG trade were then developed in Indonesia, Malaysia, and later within the region from Australia. Today, LNG reaches the Asian market from a very wide range of natural gas producing regions of the world, including the Middle East and Africa. Demand also spread beyond Japan to Taiwan, South Korea, and China, with additional developments underway in several other 
countries in the region. Natural gas pricing in Asia has historically been tied contractually to crude oil and it is only recently that alternatives have been introduced. Some current contracts are reputed to contain reference to $\mathrm{HH}$ and NBP to account for a portion of the weight in the pricing mechanisms. For many years, however, the pricing was tied to the so-called Japanese Crude Cocktail (JCC), which actually stands for Japanese Customs-cleared Crude and is an average price of a basket of crude oils that enter the Japanese market. The calorific equivalence between oil and gas is as follows: on average, one btu (British thermal unit) of natural has approximately $17.4 \%$ of the energy content of a representative JCC barrel of crude oil. Asian contracts typically include a premium: the equivalence or "slope" rate set in the contracts is typically below $17.4 \%$. The International Gas Union (2010) has estimated average slope rates for a sample between 2000 and 2008: Japan 8.8\%, Korea 11.5\%, Taiwan 4.8\%, India 11.9\%, China 9.3\%. In recent years, Asia Pacific started to move away from oil-indexation favoring more competitive gas-on-gas pricing in contracts; the degree of competition in the Asia Pacific is expected to continue to develop in the future (IEA, 2013).

Figure 2 reports recent price series for Japan, European Union, UK, and US (British Petroleum, 2012a). 


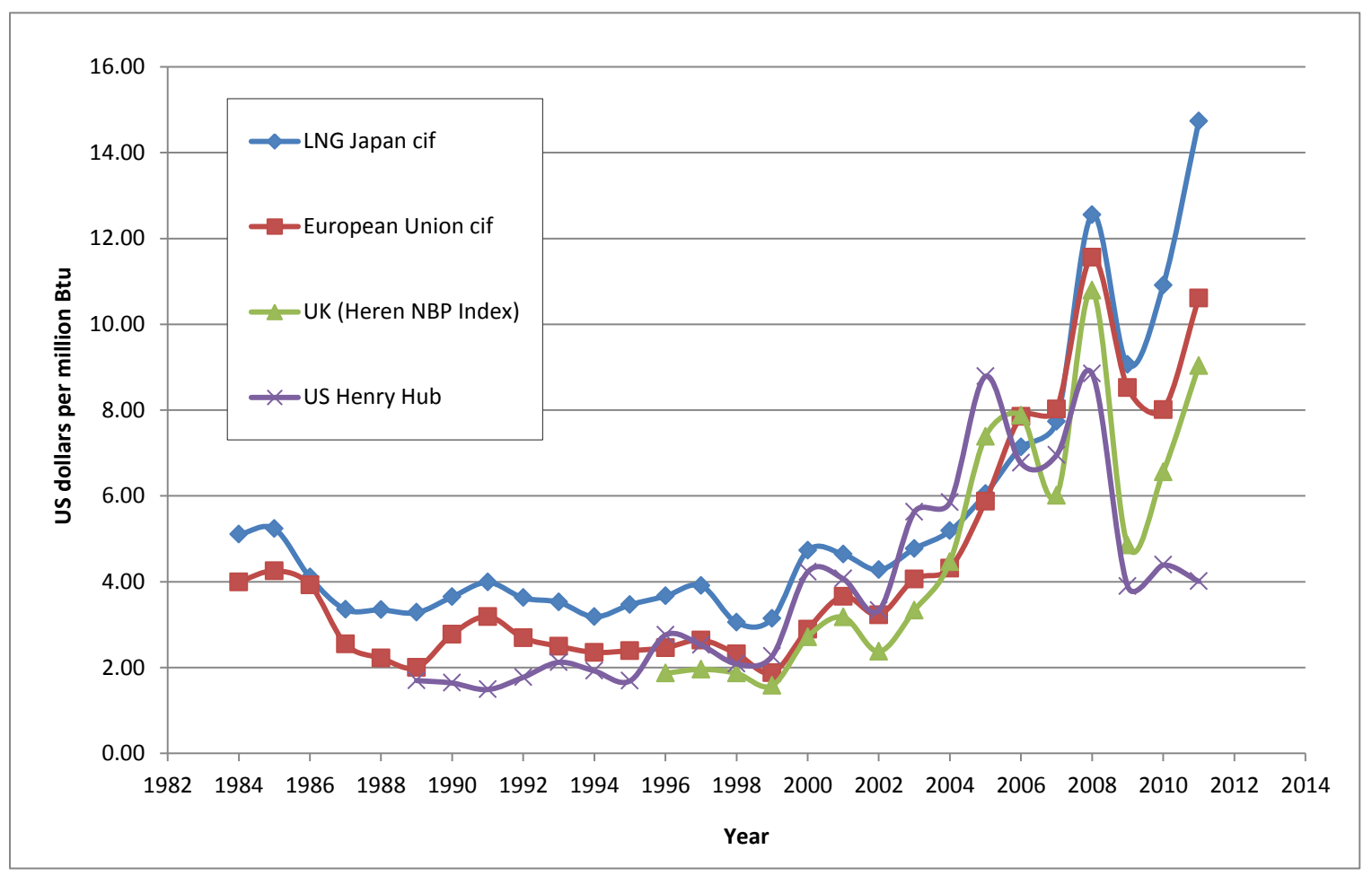

Figure 2 - Comparison of natural gas prices (Source: British Petroleum, 2012a).

The past five or so years have also seen a significant change in the balance of natural gas trade. As recently as five years ago, most analysts expected the US to become a major importer of natural gas shipped as LNG (compare net imports predictions in US EIA, 2013c, Figure 92, p. 79 and US EIA, 2008, Figure 27, p. 49). Indeed, much of the recently commissioned new LNG production and shipping capacity globally was invested in with the US market in mind. However, during this period the US has experienced what has been referred to as the "shale gale/revolution", referring to the massive expansion of natural gas production in the US from shale gas resources. The shale gas developments have significantly lowered the expectations for North American demand for LNG-shipped natural gas; and in the near future are expected to add to the sources of natural gas to be shipped as LNG. Henderson (2012) discusses the possibility of decreased gas prices in the Asia Pacific as additional supply is introduced from North American LNG exports. However, the study does not account for the 
potentially large demand increases that could result from lower prices. This, subsequently, could have the effect of raising prices again. Although we do not have regional long-term demand elasticities to quantify the changes, this would be a subject for future research. LNG from countries like Australia, US, and Canada is high cost, as would be the development of unconventional gas in China. All would presumably require breakeven prices similar to those recently observed.

In addition to the potential from unconventional gas, the Asian region is forecast to be very rich in conventional natural gas resources, especially when both yet-to-be discovered resources and the potential for reserves growth are accounted for (Aguilera and Ripple, 2011). When assessing just these potential conventional resources the Asian region appears to hold sufficient natural gas to satisfy over 140 years of current levels of consumption. Depending on the rate of development of these resources, the available volumes will have further implications for the regional pricing mechanisms that will evolve. However, it is important to note that prices in the Asia Pacific are locked into long term contracts and delinking from oil would be time-consuming and complex. Even though it would be possible to see elements of $\mathrm{HH}$ pricing co-existing with other price mechanisms, it is not evident that consuming nations would prefer this. For instance, Stern and Rogers (2011) emphasize that hub-based pricing will not unambiguously lead to natural gas prices that are lower than those currently based on crude oil or other oil products. The hub-based, gas-on-gas prices will be determined by the relative balance of supply and demand for natural gas, which may at times be "tight", leading to high prices, while at the same time the oil markets may be relatively "loose" producing low oil prices that would indicate lower oil-based natural gas prices. According to LNG Business Review (2012), Asian buyers are unlikely to want to be overly exposed to variations unlinked to their own markets. Thus, they may want to protect the existing price mechanism in spite of the higher expected prices. Producing nations within the Asia Pacific would also prefer this as it is more likely to ensure the commercial viability of their LNG and pipeline projects. 


\section{CONCLUSION}

As the Asia Pacific continues to grow, natural gas has the potential to play a significant role in satisfying energy demand. Increased use of natural gas may help to reduce dependency on oil and coal, which may result in increased energy security, reduced environmental impact, and continued economic growth. Opportunities to increase gas penetration in the short term are most likely to be found in the electricity sector, as well as the commercial and residential sectors. In the long term, possibilities may also exist in the transport sector.

The results of this study indicate that natural gas demand in the Asia Pacific should be sufficiently large to accommodate supply sources from within the region and around the world. Given that most of the potential sources of gas to the region have comparable costs of supply (Gas Strategies Group Ltd, 2012), all are likely to be competitive in the vast Asian market. Although conventional and unconventional gas resources are known to be large and widely distributed, the existence of abundant resources alone will not guarantee security of supply. Appropriate public policies that encourage investment in gas development will be essential. In the case of the Asia Pacific, the IEA (2011) estimates necessary natural gas upstream and transportation investment of 1,955 billion USD from 2011-2035. Other regions with potential to export gas to the Asia Pacific will have to invest 5,789 billion USD over the same period, though not all that investment is related to the Asia Pacific alone.

It is further necessary to consider the possibility that the energy mix in the Asia Pacific might favor natural gas more than the consensus estimates presented earlier suggest. For example, there may be 
ample opportunities for intensive coal consuming countries such as China, Australia, and India to substitute natural gas for coal and oil. These occurrences would strengthen the findings of this study.

It is recommended that energy policies in all regions should provide incentives, while not creating disincentives, for significant investment in gas development. Potentially harmful policies could come from government regulations such as price setting that keeps natural gas prices artificially low. These low prices do not provide incentives for companies to invest in the upstream, midstream, or downstream segments of the industry. Increased coal subsidies further hinder the penetration of gas into the market. Government policies in the natural gas sector that limit foreign investment (e.g. excessively high taxes and royalties) will also inhibit its contribution to the energy mix. On the other hand, increases in gas use might come from policies to address climate change, which are likely to favour gas in place of oil and coal. Some of these policies include indirect taxes on fuel and costs imposed on carbon emissions. By introducing a substantial cost on carbon, for example, the total cost of coal and gas becomes comparable, in which case relative prices determine the dominant fuel. Norton Rose Fulbright (2011) highlights key climate change policies for the Asia Pacific. Countries cited as having existing or pilot carbon pricing and trading schemes include Japan, China, Korea, India, Singapore, Indonesia, Thailand, Vietnam, New Zealand and Australia. However, the scale and pace of the projects vary and currently have little influence in determining the region's energy mix.

For both exporters and importers of natural gas, understanding the evolution of the market structure and pricing mechanisms in the region will be of critical importance. Eventually, the industry may see a shift from oil-based pricing to a gas-on-gas pricing regime with pricing hubs in China and possibly elsewhere in the region. However, it is not certain that this would lead to lower prices for gas. Regardless, it is likely that natural gas use in the Asia Pacific will continue to increase given the 
economic, environmental, and security benefits in comparison to other fossil fuels.

\section{REFERENCES}

Aguilera, R.F. and Ripple, R.D., 2011. Using size distribution to forecast natural gas resources in Asia Pacific. Applied Energy 88 (12), 4607-4620.

Aguilera, R.F. and Ripple, R.D., 2013. Modeling primary energy substitution in the Asia Pacific. Applied Energy 111, 219-224.

British Petroleum, 2012a. Statistical Review of World Energy 2012. British Petroleum, London.

British Petroleum, 2012b. Energy outlook 2030. British Petroleum, London.

British Petroleum, 2013. Energy outlook 2030. British Petroleum, London.

Bureau of Resources and Energy Economics, 2012. Resources and energy quarterly (September). Australian Government Department of Resources, Energy and Tourism, Canberra.

Clemen, R.T., 1989. Combining forecasts: A review and annotated bibliography. International Journal of Forecasting 5 (4): 559-583.

Dahl, C.A., 2004. International energy markets: understanding pricing, policies, and profits. PennWell Corporation, Tulsa, Oklahoma.

DIW Berlin (German Institute for Economic Research), Huppmann, D., Egging, R., Holz, F., Ruester, S., Hirschhausen, C., Gabriel, S.A., 2009. The world gas market in 2030 - development scenarios using the world gas model. Discussion paper 931, Berlin.

ExxonMobil, 2012. The outlook for energy: a view to 2040. ExxonMobil, Irving, Texas. 
Gas Strategies Group Ltd, 2012. Will China have its own shale gas revolution? Gas Matters, September, London.

Henderson, J., 2012. The potential impact of North American LNG exports. The Oxford Institute for Energy Studies, NG 68, Oxford.

International Energy Agency, 2011. World energy outlook. Organization for Economic Cooperation and Development, Paris.

International Energy Agency, 2012. World energy outlook. Organization for Economic Cooperation and Development, Paris.

International Energy Agency, 2013. Developing a natural gas hub in Asia. Organization for Economic Cooperation and Development, Paris.

International Gas Union, 2009. Natural gas industry study to 2030: enabling solutions for energy demand and environmental challenges. International Gas Union, Norway.

International Gas Union, 2010. Irrational LNG pricing impedes development of Asian natural gas markets: A perspective on market value. International Gas Union, Norway.

LNG Business Review, 2012. Will US LNG exports upset the JCC linkage in Asian LNG contracts? LNG Business Review 5 (6), 4-9.

Massachusetts Institute of Technology Center for Energy and Environmental Policy Research, Paltsev, S., 2011. Russia's natural gas export potential up to 2050. Study on the future of natural gas: supplementary paper SP3.1, Cambridge.

Norton Rose Fulbright, 2011. Asia Pacific climate change policy series - climate change commitments in Asia Pacific: a green revolution? Norton Rose Fulbright LLP, May, London.

http://www.nortonrosefulbright.com/knowledge/publications/30206/asia-pacific-climate-changepolicy-series

Platts, Khrennikova, D., 2011. Turkmenistan to increase gas supplies to China to $65 \mathrm{bcm}$ per year. Platts News \& Analysis, 24 November, Moscow. 
Platts, 2013. Australia could overtake Qatar as top LNG exporter by 2020 - study. Platts McGraw Hill Financial, 9 April, London.

Stern, R. and Rogers, H., 2011. The transition to hub-based gas pricing in continental Europe. The Oxford Institute for Energy Studies, NG49, Oxford.

TOTAL, Verdier, C., 2012. Why the global gas market is full of surprises. Presented at the Gastech Conference and Exhibition, 8-11 October 2012, London.

US Energy Information Administration, 2008. Annual energy outlook 2008. US Department of Energy, Washington DC.

US Energy Information Administration, 2013a. Technically recoverable shale oil and shale gas resources: an assessment of 137 shale formations in 41 countries outside the United States. US Department of Energy, Washington DC.

US Energy Information Administration, 2013b. International energy outlook. US Department of Energy, Washington DC.

US Energy Information Administration, 2013c. Annual energy outlook 2013. US Department of Energy, Washington DC.

\section{End Notes}

${ }^{\mathrm{i}}$ Asia Pacific $=$ Afghanistan, American Samoa, Australia, Bangladesh, Bhutan, Brunei, Cambodia, China, Fiji, French Polynesia, Gilbert-Kiribati, India, Indonesia, Japan, Korea (DPR), Laos, Malaysia, Maldives, Mongolia, Myanmar, Nepal, New Caledonia, New Zealand, Papua New Guinea, Pakistan, Philippines, Republic of Korea, Singapore, Solomon Islands, Sri Lanka, Taiwan, Thailand, Tonga, Vanuatu, Vietnam, Western Samoa 